\section{Tamarin and Marmoset Mating Systems: Unusual Flexibility}

\author{
Anne Wilson Goldizen
}

Recent studies of wild tamarins and marmosets have shown that at least one species exhibits variable mating patterns, including cooperative polyandry, monogamy and, more rarely, polygyny. Polyandry is thought to occur because the high frequency of twinning and the relatively high weights of infants in these species make the rearing of infants unusually difficult. Nonreproductive Gelpers (older offspring) and polyandrous males may serve as alternative sources of the extra help needed with infant care. The apparent causes of facultative polyandry in saddle-back tamarins are quite different from those of the cooperative polyandry that has been studied in some bird species.

In cooperative polyandry, two males copulate with a single female, and then cooperate to raise her subsequent offspring 1 . Evolutionary theory suggests that polyandry should be infrequent because males typically increase their reproductive success by maximizing the number of females they fertilize, while females increase their reproductive success by maximizing their access to food resources $^{2,3}$. Nonetheless, cooperative polyandry has been observed in about ten bird species ${ }^{1,4,5}$, some Asian human groups ${ }^{6}$ and at least one tamarin species (the saddleback tamarin, Saguinus fuscicollis $)^{7}$.

In this article I review the evidence suggesting that saddle-back tamarins frequently mate polyandrously and discuss whether other members of the callitrichid family are likely to exhibit polyandry. I also describe the hypotheses that have been proposed to explain the occurrence of cooperative polyandry among tamarins. Finally, I compare the cooperative polyandry of tamarins to that found in birds.

Tamarins and marmosets are the smallest (weighing 100-800 g) of all anthropoid primates and also the only family that regularly produces (wins lover $80 \%$ of pregnancies) ${ }^{8}$. Unlike other primates, adult male

A.W. Goldizen is at the Dept of Anthropology, 1054 LSA Bldg, University of Michigan, Ann Arbor, MI 48109, USA. callitrichids generally provide as much or more parental care than the infants' mothers ${ }^{9,10}$. In addition, in all callitrichid species that have been studied, nonreproductive individuals 1-4 years old and still living in their natal groups provide substantial help in raising infant siblings ${ }^{9}$, as occurs in avian helperat-the-nest species 5.11 . (See Box 1 for a summary of callitrichid ecology.)

\section{History of the study of callitrichid social systems}

Several species - especially saddle-back tamarins, cotton-top tamarins (Saguinus oedipus), golden lion tamarins (Leontopithecus rosalial and common marmosets (Callithrix jacchus) - have been studied intensively in captivity for about two decades ${ }^{12-14}$. Reports of the first major ficld studics of callitrichids (both on cotton-top tamarins) did not appear until 197815-17. Even up to now, there have been few studies of the behavior and social organization of wild callitrichids, because of the great difficulty of observing small, quiet wild animals in the rain forest. Behavioral studies of individually marked animals have been carried out with only five species: the common marmoset ${ }^{18}$, the golden lion tamarin ${ }^{19}$, the saddle-back $\operatorname{tamarin}^{7,20}$, the emperor tamarin (S. imperator) (Goldizen, unpublished) and the moustached tamarin (S. mystax) ${ }^{21,22}$.

As a result of early studies, tamarins and marmosets were considered to be obligately monogamous, living in extended family groups consisting of breeding pairs and their young 23,21 . This conclusion was based on two observations. First, all wild groups that had been observed contained only single breeding females and single sets of young of similar age 9,10 . Second, captive animals seemed to fare best when kept either as lone pairs or pairs with offspring. Vicious fighting often occurred when extra adults of either sex were introduced.

Callitrichid mating patterns, however, were still somewhat puzzling: first, some wild groups seemed rather too large to be extended families ${ }^{16,17}$; secondly, most wild groups contained more adult males than females 9.10 ; and thirdly, the early studies of cottontop tamarins showed that individuals frequently transferred between groups ${ }^{16,17}$

\section{Variable mating systems in tamarins}

A seven-year study of wild saddle-back tamarins (Fig. 1) in the Manú Park, southeastern Peru, was the first study of wild callitrichids involving animals that were both individually marked and sufficiently habituated to the presence of humans to allow detailed observations of their behavior. This population was found to have a more complex social system than expected. Monogamous, polyandrous and polygynous groups occurred $^{7,20}$. Although the relative frequencies of these mating patterns in the population were not known precisely, polyandry appeared to be the most frequent and polygyny the least common. In addition, all individuals two years of age or older that were still in their natal groups helped to raise their full or half siblings 7,20 .

The following observations constitute the evidence that some saddle-back tamarins mated polyandrously

(1) In five of six instances in which copulations were observed in groups having two adult males, both males copulated 7,20 . In one of these groups, one male was observed copulating with the group's only female 31 times, while 25 matings involved the other male ${ }^{20}$. Saddle-back tamarins mate at all times of year, even during pregnancy and lactation, and females show no morphological or behavioral signs of estrus.

(2) In five multi-male groups in which infant carrying was quantified, all of the adult males present undertook significant amounts of infant carrying 7,20

13) All of the new groups that formed within the study area consisted of either two adult males and an unrelated female $(n=3)$ or two adult males and two adult females $(n=1)(\operatorname{Ref} 7$; Goldizen, unpublished). 
14) In two separate instances, an adilt male was known to join a grcup that contained a previously monogamous pair. In at least one of these cases the trio then remained together for more than one year.

Two groups were considered to be polygynous. One of these contained two parous females and two sets of young less than six months old $^{7}$. In the second group two fernales became pregnant within one month of each other ${ }^{20}$

Adult group compositions are not neizessarily indicative of mating patterns because some individuals rernain in their natal groups in nonbreeding positions until well past adulthood. Nonetheless, the adult grcup compositions that occurred in this saddle-back tamarin population illustrate the variability of this species' social organization (Fig. 2).

Wild populations of many or all callitrichid species may have variable mating systems similar to those of saddle-back tamarins. This is suggested by data showing that in all species so far studied, groups with only one adult male and one adult female are rare, and migrations of individuals of both sexes be ween groups are common $9.10,25$. These data on the frequency of changes in group composition due to immigrations and emigrations of adults suggest that the extra adults observed in many groups are not all older offspring born in those grcups $^{25}$

Unfortunately, there are very few data on the mating patterns of other callitrichid species. In both moustached tamarins and golden lion tamarins, wild groups with two simultaneously breeding females have been seen ${ }^{19,26}$. Data on group compositions suggest that polyandry occurs in moustached tam$\operatorname{arins}^{21}$ and emperor tamarins (Fig. 3; Goldizen, unpublished). In golden lion tamarins, polyandry is suspected because of observations of two males mating with the same fenale ${ }^{19}$. However, these findings should be considered tentative until more data on copulations are available.

\section{Why helpers are necessary in tamarins}

Helpers are individuals that care for young that are not their own 27 . Nonreproductive helpers occur in all callitrichid species that have been studied in captivity9,10. The polyandrous males found in saddle-back tamarins and perhaps other species are called reproductive helpers here, because they care for young which may or may not be their own.

The key to explaining helpers and polyandry in tamarins appears to be the cost of parental care $^{7,20,21,25}$. Only one of 33 observed sets of young born in a wild population of saddle-back tamarins was born to a lone adult pair, and even this pair had been part of a two-male one-female trio ceived. One of the males disappeared soon after the female conceived. In fact, groups consisting of lone monogamous pairs rarely occurred in the population ${ }^{20}$ Thus, there are almost no data on whether lone pairs of callitrichids are capable of rearing young in the wild. However, the fact that they almost never try to do so suggests that they would rarely be successful.

The dependency of breeding pairs of tamarins on helpers is thought to stem from the high weight of twin infants $7,20,21,25$. The combined weight of twins at birth is about $20 \%$ of the mother's weight and at the age of weaning and locomotor independence is about $50 \% 24$. Lactating female tamarins need to eat approximately twice as at the time the infants were con-

Box 1 . A summan of tanarin and ma moset ecoloc, 0

Although the taxonomy of callitrichids is still debated there are approximately 15 species in two genera of tamarins, Saguinus and Leontopithecus, and two genera of marmosets, Cebuella and Callithrix ${ }^{3}$. All species are arboreal residents of Central or South American forests where they live in groups with an average of five or six members.

Tamarins and marmosets eat insects and fruits and, occasionally, small vertebrates, nectar and tree exudates (sap and gum). The two groups differ in the kinds of plant food they eat, while at least some species within the genus Saguinus differ in their methods of insect hunting Marmosets have unusually long lower incisors, which are specialized for chewing holes in tree trunks and branches from which the marmosets later harvest sap and/or gum. At least two species, pygmy marmosets (Cebuella pygmaea) and common marmosets, obtain the majority of their plant food from such exudates. Typically, a home range includes several trees from which the marmosets feed intensively. The home ranges of marmosets are quite small $(0.2-12.0 \mathrm{ha}$, and groups travel $280-1500 \mathrm{~m}$ per day.

Tamarins do not have specialized incisors. Although they often feed on exudates flowing from marmoset-made holes or other tree wounds, they cannot themselves cause exudate flow. Instead, they obtain most of their plant food from fruits, eating lesser amounts of exudates and nectar. The home ranges and day ranges of tamarins are larger than those of mamosets $17.8-100.0$ ha. 1000-2061 m, respectively). This may be because individual trees only produce fruits over short periods and, thus, fruits are more unpredictably available and perhaps more widely scattered than are marmosets exudate trees.

Most callitrichid species that have been studled have been found to defend teritories at least in some locations. However, both cotton-top tamarins and saddle-back tamarins have greatly overlapping home ranges in some locations and virtually exclusive territories in others.

much as nonlactating females or adult males ${ }^{20,28}$. Presumably, the high weight of infants also causes

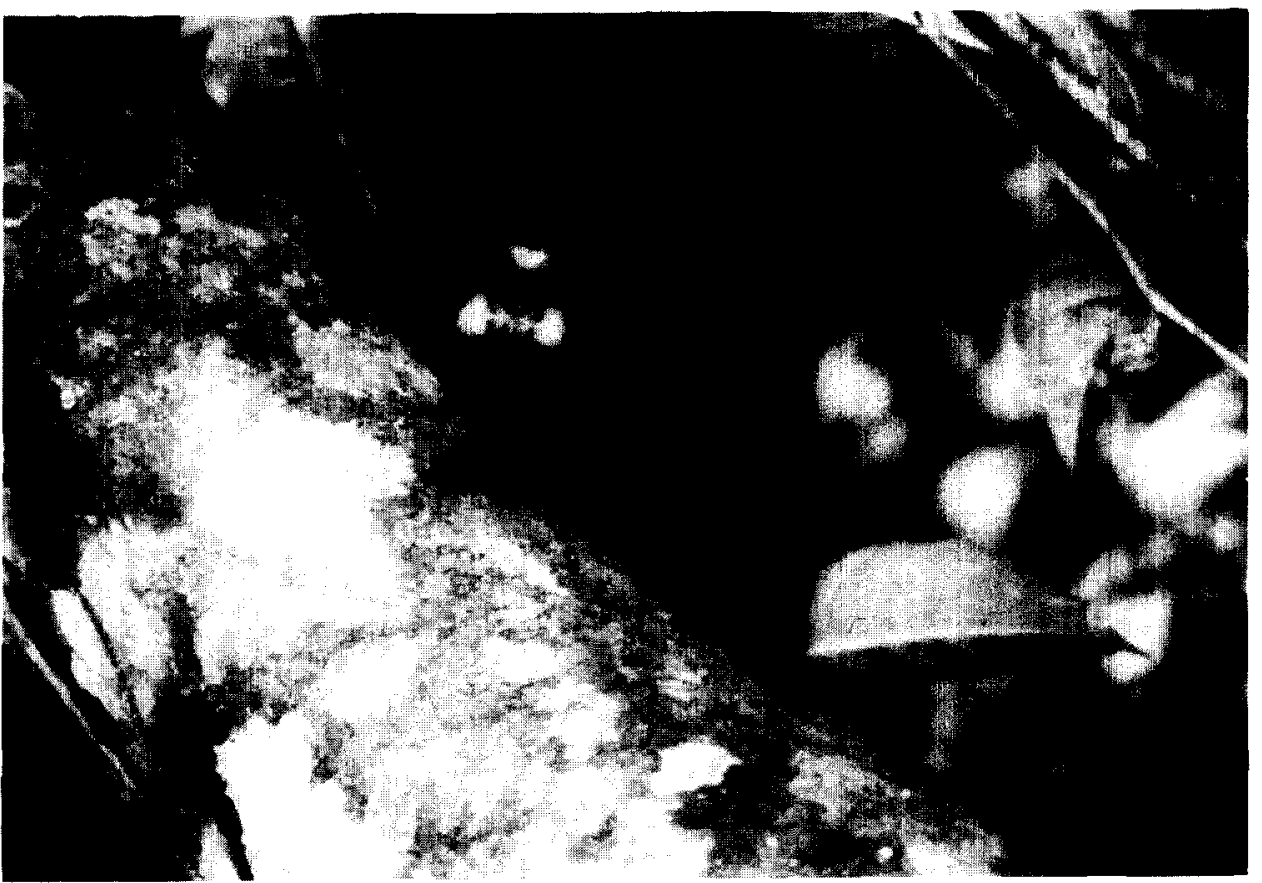

Fig. 1. Four month old juvenile saddle-back tamarin. Photo by Anne Goldizen. 


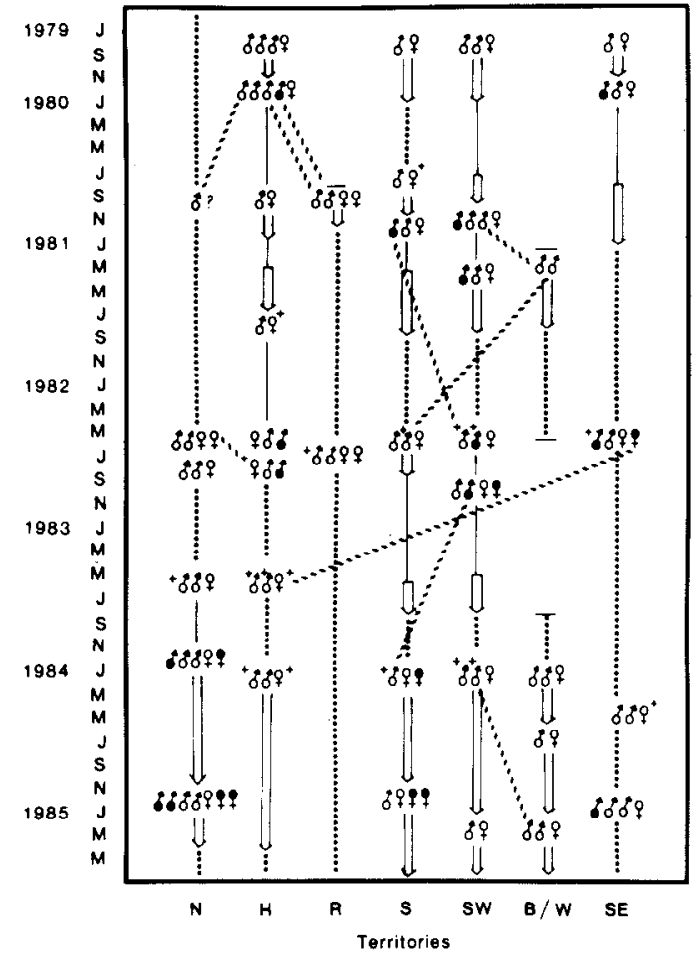

infant carrying (Fig. 4) to be energetically costly, especially since wild tamarins carry young infants at all times and travel over a kilometer per day on average ${ }^{9,10}$. Infant carrying seems to reduce potential feeding time in saddle-back tamarins; adults spent significantly less time feeding when they had infants on their backs than when they did $\operatorname{not}^{20}$.

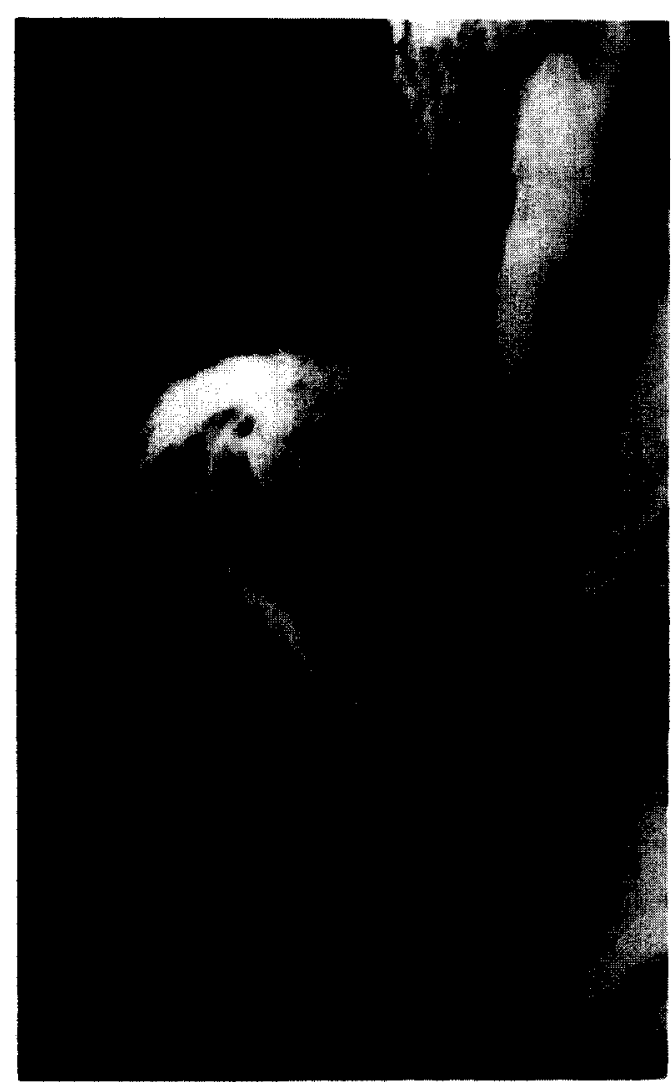

Fig. 3. Approximately five month old emperor tamarin. Photo by Anne Goldizen.
Fig. 2. Adult compositions over six years of seven saddle-back tamarin groups living in Peru's Manú National Park. Double lines represent compositions observed at least once a month; single lines represent groups whose adult compositions did not change over periods when observers were absent from the study site; dotted lines represent unknown compositions during prolonged intervals when observers were unable to check the groups, usually during the observers absences from the site; dashed lines indicate transfers between groups. Symbols: $\sigma^{\prime}$ adult male; $q$ adult female; $\gamma$, $q$ animals that had reached adulthood within their natal group; $(+)$ indicates replacements of adult males and females; - troop formation or extinction.

Periods of lactation and infant carrying overlap closely. The increased feeding requirements of females during lactation as well as the reduced time they have for feeding while infant carrying probably explain why wild saddle-back tamarin mothers do only about $20 \%$ of the carrying of their infants (Table 1). To compensate, reproductively active males carry about twice as much as mothers. A similar division of infant carrying by sex was found in a wild group of moustached tamarins ${ }^{22}$. Infant carrying by breeding males presumably increases the reproductive success of those males, on average. If males did not help, females would probably not be able to do all of the necessary carrying and infants would be unlikely to survive. Males are probably able to carry more than females because the males do not suffer the energetic costs of lactation.

\section{Reasons why nonreproductive callitrichids serve as helpers}

To explain why nonreproductive individuals help others to rear offspring one must answer the following questions ${ }^{5}$. (I) Why do these individuals not breed? (2) Given that they are not breeding on their own, why do they remain in a group with other breeders? (3) Given that they are in a group with other individuals, why do they actively help to care for the young of those individuals? There is too little information on wild callitrichids to be able to do anything more than speculate about these questions. It does appear likely that the risk of predation would be very high for a lone tamarin and that this may ex- plain why nonreproductive tamarins remain in their natal groups. Tamarins are vulnerable to many species of raptors, felids and snakes $^{10}$, and are constantly vigilant.

The helping behavior of nonbreeding individuals still in their natal groups may be explained by inclusive fitness benefits gained from increasing the reproductive success of close relatives. It has also been found from laboratory studies that female tamarins, and to a lesser extent males, have poor success at raising their own offspring if they do not first help to care for their infant siblings ${ }^{29-31}$. Therefore, tamarin helpers appear to benefit by gaining experience. However, experiments have not yet been done to distinguish whether individuals must actively care for their siblings to gain the experience, or if simply watching others care for young is sufficient.

\section{Possible causes of facultative polyandry in tamarins}

In a discussion of possible polyandry (called 'female promiscuity') in moustached tamarins, it was noted that the number of adult males in a group appeared to have an effect on the survivorship of young ${ }^{21}$. This led to the hypothesis that female promiscuity functions to ensure that multiple adult males remain in the female's group and help care for infants ${ }^{25}$

A somewhat different hypothesis explaining facultative polyandry in saddle-back tamarins states that for a high probability of infant survival, three or more caregivers are needed but that these can include either nonreproductive helpers or polyandrous males ${ }^{20}$. This hypothesis suggests that the mating system of a group is determined primarily by the number of older offspring still present in the group. The hypothesis generates the following predictions: (1) a pair with older offspring still in their group would mate monogamously because the older offspring would serve as helpers; (2) a pair without older offspring would need extra help with infant care and would form a polyandrous trio by allowing a second male to join them and mate with the female. The second male would help to care for the 
subsequent infants because of the possibility that he could have fathered them. Females would be likely to benefit more from being pclyandrous than would males, but this hypothesis states that in some circumstances even males would benefit. While preliminary data frcm saddle-back tamarins support these predictions, they must be tested further.

The high frequency of twinning and the heavy weight of twin infants at birth relative to the mother's weight appear to lead to the need for helpers, and thus facultative polyandry, in saddle-back tamarins. Since these two factors are true of all the callitrichids, the prediction thiat all callitrichid species will be found to be facultatively polyandrous seems reasonable ${ }^{25}$.

However, because the benefits of polyandry to the individuals invclved appear to depend on the overall costs of rearing infants, and these costs may differ between genera, species, or even populations of a single species, the be:nefits and thus the frequency of polyandry may differ between these groups. For instance, since marmosets tend to cover shorter daily distances than tamarins (Box 1). and therefore do not have to carry infants as far, polyandry might be: predicted to be less frequent in marmosets than in tamarins.

\section{Comparisons with cooperatively} polyandrous birds

The cooperative polyandry exhibited by saddle-back tamarins appears to be quite different from that of dunnocks (Prunella modularis), in which cooperative polyandry has been intensively studied $^{32}$. In these birds, dominant males apparently do not benefit from being polyandrous. Whether a disnnock male is able to mate monogamously depends on the size of a female's territory. A male woose female's territory is largc cainnot always prevent a subordinate male from mating with the female. Such males are therefore unable to prevent polyandrous matings. While trios of dunnocks do raise more offspring thar pairs, the $\mathrm{d}$ fference appears not to be great enough for dominant males to benefit from being polyandrous. $T$ lis may be a critical difference

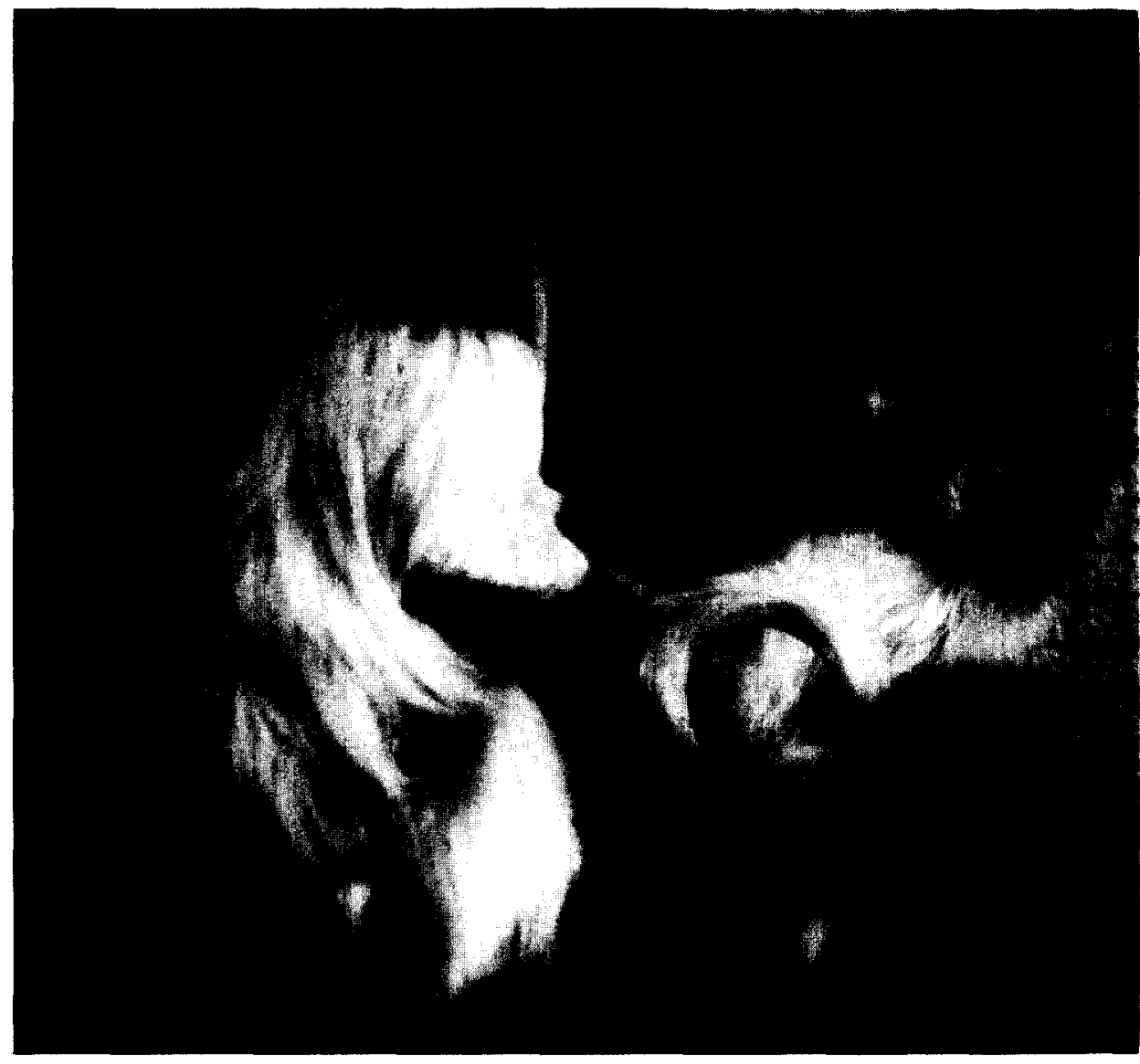

Fig. 4. Infant golden lion tamarin carried on the back of an adult male, with an adult female on left. Photo by Jeffrey French.

between tamarin polyandry and dunnock polyandry.

In some other cooperatively polyandrous birds, however, males perhaps benefit from mating polyandrously ${ }^{4,5}$. For example, with large pools of nonbreeding some young male Galápagos hawks (Buteo galapagoensis) appear to benefit from polyandry because of their much higher survival in trios than as solitary floaters; on islands

Table 1. The carrying of infants by wild saddle-back tamarins of different age-sex classesa.

Age-sex class

Proportion of infant carrying (mean \% $\%$ sD)
No. of individuals
Adult females (mothers)

Males $\geq 3$ years old

3 year old nonreproductive females

2 year old nonreproductive females

2 year old nonreproductive males

1 year old females

1 year old males

$\begin{array}{ll}19.2 \pm 3.3 & 4 \\ 31.0 \pm 14.5 & 9 \\ 24.4 & 1 \\ 12.2 & 1 \\ 6.9 & 1 \\ 6.4 \pm 5.9 & 2 \\ 5.6 \pm 3.6 & 3\end{array}$

aData are combined from four groups studied during two different years. For each individual the mean percentage of its group's infant carrying that it did during a season was calculated, and then these were averaged by age-sex class. Only one individual is included twice in these data - once as a 1 year old male and once as an adult male. Some of the adult males included in this table were probably not reproductively active: this might explain why the figure of $31 \%$ for the average amount of carrying done by adult males is less than the figure of about $40 \%$ that is presented in the text as an average for males known to have been reproductive. These data are taken from Refs 7 and 20 
birds, young males do not have the option of initially breeding in pairs $^{33}$. Tasmanian native hen (Tribonyx mortierii) males have limited opportunities to mate monog amously because of a male-biased sex ratio; polyandrous matings are an adaptive alternative because trios raise more young than pairs, and because polyandrous males tend to be closely related ${ }^{34}$. In neither of these species, however, are the high costs of parental care the primary reason for polyandry, as appears to be the case in tamarins. Thus, cooperative polyandry seems not to be a phenomenon with a single cause, but to occur in different species for different reasons.

\footnotetext{
Acknowledgements

I thank F.S. Dobson, H.L. Gibbs, A. Gol dizen, M. Hauser, G. Hill, M. Symington and L. Tabak for commenting on earlier drafts of the manuscript. The Dirección Forestal y de Fauna of the Peruvian Ministry of Agriculture and the staff of the Manú National Park kindly allowed me to study the lamarims in the Manú Park. The research on saddle-back tamarins was supported by NSF grants DEB79-04750 and BNS79-15079 to John Terborgh and BSR83-11782 to A. Goldizen, the Wenner-Gren Foundation, the Joseph Henry Fund of the National Academy of Sciences, the T.C. Schneirla Foundation, Sigma Xi The Scientific Research Society, and various grants from the University of Michigan.
}

\section{References}

I Faaborg, I. and Patterson, C.B. (1981) Ibis $123,477-484$

2 Bateman, A.J. (1948) Heredity 2, 349-368 3 Trivers, R.L. (1972) in Sexual Selection and the Descent of Man, 1871-1971 (Campbell, B., ed.I, pp. 136-172, Aldine

4 Oring, L.W. $\{1986$ ) in Current Ornithology (Vol. 3) (Johnston, R., ed.), pp. 309-351, Plenum Press

5 Brown, J.L. (1987) Helping and Communal Breeding in Birds: Ecology and Evolution. Princeton University Press

6 Crook, J.H. and Crook, S.J. in Human Reproductive Behavior: A Darwinian Perspective (Betzig, L., Borgerhoff Mulder, $M$. and Turke, P., eds), Cambridge University Press (in press)

7 Terborgh, I. and Goldizen, A.W. (1985) Behav. Ecol. Sociobiol. 16, 293-299

8 Hershkuvilz, P. 11977। Living New World Monkeys (Platyrrhini) (Vol. 1), University of Chicago Press

9 Goldizen, A.W. (1987) in Primate Societies ismuts, B.B., Cheney, D.L., Seyfarth, R.L. Wrangham, R.W. and Struhsaker, T.T., eds), pp. 34-43, University of Chicago Press 10 Sussman, R.W. and Kinzey, W.G. (1984) Am. I. Phys. Anthropol. 64, 419-449 11 Emlen, S.T. (1984) in Behavioural Ecology: An Evolutionary Approach (Krebs. I.R. and Davies, N.B., eds I, pp. 305-339, Sinauer Associates

12 Epple, G and Katz, Y. 119831 in Reproduction in New World Prindates (Hearn, J.P., ed.), pp. 115-148, MTP Press 13 Hearn, I.P. (1983) in Reproduction in New World Primates (Hearn, J.P., ed.I, pp. 181-215, MTP Press

14 Snowdon, C.T. and Soini, P. in Ecology and Behavior of New World Primates (Vol. 2 (Mittermeier, R.A. and Coimbra-Filho, A.F eds). Academia Brasileira de Ciencias, Rio de Janeiro (in press)
15 Dawson, G.A. 119791 Folia Primatol 31 253-284

16 Neyman, P.F. 11978 ) in The Biology and Conservation of the Callitrichidae (Kleiman, D.G., ed.), pp. 30-72, Smithsonian Institution Press

17 Dawson, G.A. (1978) in The Biology and Conservation of the Callitrichidae (Kleiman. D.G., ed.I, pp. 23-38, Smithsonian Institution Press

18 Hubrecht, R.C. $|1984|$ Primates 25, 13-21

19 Dietz, J.M. and Kleiman, D.G. $(1986)$ Primate Report 14,77

20 Goldizen, A.W. 11987) Behav. Ecol. Sociobiol. 20, 99-109

21 Garber, P.A., Moya, L. and Malaga, C. (1984) Folia Primatol. 42, 17-32

22 Garber, P.A. (1986) Primate Report 14, 78 23 Eisenberg, J.F., Muckenhirn, N.A and Rudran, R. (1972) Science 176, 863-874 24 Kleiman, D.G. (1977) O. Rev. Biol. 52 39-69

25 Sussman, R.W. and Garber, P.A. (1987) Int 1. Primatol. 8, 73-92

26 Ramirez, M. (1984) Am. J. Primatol. 7 245-259

27 Skutch, A.F. 11961$)$ Condor 63, 198-226 28 Kirkwood, J.K and Underwood S.J (1984) Folia Primatol. 42, 180-187

29 Epple, G. (1975) Folia Primatol. 24,

$221-238$

30 Hoage, R.H. (1978) in The Biology and Conservation of the Callitrichidae (Kleiman, D.G., ed.I, pp. 293-305, Smithsonian Institution Press

31 Tardif, S.D., Richter, C.B. and Carson, R.L. (1984) Am. J. Primatol. 6, 377-380

32 Davies, N.B. and Houston, A.I. 11986

I. Anim. Ecol. 55, 139-154

33 Faaborg, I., deVries, T., Patterson, C.B. and Griffin, C.R. 11980$\}$ Auk 97, 581-590

34 Maynard Smith, J. and Ridpath, M.G. (1972) Am Nat 106, 447-452

\section{The Relationships of the Major Group of Mammals: New Approaches}

\section{Michael J. Benton}

Systematically, mammals must be the most intensively studied group of organisms. Yet the relationships between the maior orders - bats, whales, primates, rodents, insectivores, elephants, and so on - are still controversial. New systematic approaches, including molecular sequencing studies and cladisitic analyses of morphological data, have given rise to a number of new phylogenetic hypotheses, but only a few sister-group relationships seem to have general support. These hypotheses are depicted in the accompanying centrepage diagram.

Michael Benton is at the Dept of Geology. The Queen's University of Belfast, Belfast BT7 INN, UK.
The Class Mammalia is generally divided into three subclasses: Monotremata, Metatheria (marsupials) and Eutheria (placentals). Monotremata are regarded as the sister group of the Metatheria plus Eutheria (= Theria) since the latter two groups share several derived characters (synapomorphies) such as separate anal and urogenital openings, loss of the eggshell, and mammary glands with teats. The various orders of Eutheria are grouped together since they all share the chorioallantoic placenta, prolonged gestation, a median vagina, and several other synapomorphies. The problems in clas- sification concern the arrangement of the 18 or so placental orders

An early phylogeny of placental mammals was presented by Gregory ${ }^{1}$ in 1910 (see centrepage diagram I. Gregory grouped edentates with pholidotans (pangolins), and rodents with lagomorphs (rabbits)-two fairly unsurprising associations. He also linked primates with scandentians (tree shrews), and those two with chiropterans (bats) plus dermopterans (flying lemurs), in a major group termed Archonta, and all four of these with insectivores. This kind of grouping has also appeared in various other proposed classifications. The most striking part of Gregory's scheme of relationships is that he split up the ungulates, the moderate- and large-sized hoofed plant-eaters. He paired the artiodactyls (pigs, cattle, deer) with 